\title{
MODEL INFORMATION DASHBOARD NILAI SISWA: TOOLS MONITORING HASIL BELAJAR
}

\author{
Husein Muhammad Fahrezy ${ }^{1}$,Toga Parlindungan Silaen ${ }^{2}$, Henderi ${ }^{3}$ \\ Program Studi Magister Teknik Informatika, Universitas Raharja ${ }^{1,2}$, \\ Penulis Korespondensi, Program Studi Teknik Informatika, Universitas Raharja ${ }^{3}$ \\ JL. Jendral Sudirman No.40 Tangerang, Indonesia \\ Sur-el : husein@ raharja.info',parlin@ raharja.info²,henderi@ raharja.info ${ }^{3}$
}

\begin{abstract}
In teaching and learning activities it is necessary to have monitoring activities carried out by teachers to the principal, so that the teaching staff know the values and limits of the ability of their students. The process of delivering information about the grades of students to the principal is still manually and less than optimal. So we need a system that makes it easy for teachers to monitor their students. Therefore, the discussion in this paper is to design a dashboard information model that will facilitate collaboration between teachers and monitor the development of students' abilities by the principal. This research uses the needs analysis, planning, prototype design and prototype review methods. So the data displayed will be in accordance with what is needed by the school. With the dashboard information will provide teaching staff information that is as needed, interactive and more efficient.
\end{abstract}

\section{Keywords:Information, Dashboard, Monitoring, evaluation}

\begin{abstract}
Abstrak: Pada kegiatan belajar mengajar diperlukan adanya kegiatan pemantauan yang dilakukan oleh para guru sampai kepala sekolah, agar tenaga pengajar mengetahui nilai dan batas kemampuan para murid-muridnya. Proses penyampaian informasi mengenai nilai para murid kepada kepala sekolah masih dilakukan secara manual dan kurang maksimal. Sehingga diperlukan sistem yang mempermudah tenaga pengajar dalam memonitor muridnya. Maka dari itu, pembahasan yang ada di dalam paper ini adalah merancang sebuah model dashboard information yang akan mempermudah kolaborasi antar guru dan pemantuan perkembangan kemampuan para murid oleh kepala sekolah. penelitian ini menggunakan metode analisa kebutuhan, perencanaan, perancangan prototype dan review protoype. Sehingga Data yang ditampilkan akan sesuai dengan yang dibutuhkan pihak sekolah. Dengan adanya dashboard information akan memberi para tenaga pengajar informasi yang sesuai kebutuhan, interaktif dan lebih efisien.
\end{abstract}

Kata kunci: Informasi, Dashboard, Monitoring, Evaluasi

\section{PENDAHULUAN}

Pesatnya perkembangan teknologi menuntut pihak sekolah untuk dapat meningkatkan kualitas mengajar. Kemudahan dalam mengakses informasi nilai dan kemampuan para murid pun dibutuhkan untuk meningkatkan kualitas pengajar. Proses pengembangan dalam kegiatan belajar dan mengajar lebih efektif. Tenaga pengajar seperti guru memerlukan media agar mempermudah kolaborasi antar guru untuk melihat hasil belajar murid yang sama agar lebih mudah memantau murid yang dimaksud tanpa harus meminta data tentang seorang murid yang dimaksud ke guru lain.

Permasalahan yang sama dalam penelitian Mulyono [1] membahas tentang pengunaan dashboard sebagai penyajian informasi tingkat pelanggaran disiplin siswa, dimana dashboard adalah bentuk penyempurnaan cara menyajikan data, dashboard salah satu bagian dari business 
intelligence yang menampilkan informasiinformasi penting yang memudahkan pengguna informasi dalam mengambil keputusan secara strategis. Dalam penelitian mulyono menggunakan dashboard sebagai media informasi untuk mengatasi masalah sulitnya mengakses informasi tentang pelanggaran disiplin siswa. Dari permasalahan ini maka penulis tertarik untuk merancang sebuah dashboard yang akan memangkas sistem tersebut sehingga lebih memudahkan tenaga pengajar.

Begitu juga pada penelitian Henderi, et al [2] yang membahas tentang pengembangan dashboard montoring system sebagai solusi dari permasalahan sistem pengolahan data penjualan transaksional. Penelitiannya dilaksanakan karena pengolahan data di objek penelitian masih menggunakan excel, berbentuk table, dan penuh angka. Ada ribuan kolom transaksi yang pengolahan datanya butuh waktu lama, sehingga berpotensi menimbulkan kesalahan pengolahan.

\begin{tabular}{crr}
\multicolumn{2}{c}{ Penggunaan } & dashboard yang \\
memudahkan proses monitoring dan
\end{tabular}
pengambilan keputusan juga sesuai dengan penelitian Ropianto [3] Pemanfaatan sistem dashboard dapat membantu pihak STT Ibnu Sina Batam dalam memantau atau memonitor performa akademik pada perguruan tinggi yang dipimpinanya. Serta bisa dipergunakan sebagai landasan pengambilan keputusan. Data-data yang ditampilkan berupa data-data yang berisi informasi yan bersifat kritis. Sementara dalam penelitian Untung, et al [4] peng-implementasian dashboard yang menyampaikan informasi nilai keseluruhan satu kelas dan mahasiswa dapat mengetahui berapakah nilai tertinggi dan berapakah nilai terendah di kelasnya secara online membuat penyampaian informasi lebih efisien.

Pengelolaan data sekolah, khususnya data nilai murid mengandung informasi yang penting. Apabila yang di kelola dalam junlah banyak tentu akan membuat kewalahan pihak sekolah. Pegelolaan data yang dilakukan sekolah masih menggunakan bentuk tabel, sehingga membuat proses pelaporan kepada kepala sekolah lebih lama dan kurang efisien. Berdasarkan permasalahan itu, penelitian ini akan membahas model information dashboard nilai siswa yang akan digunakan pihak sekolah dalam memonitoring nilai para murid. Sehingga penyampaian informasi akan lebih efisien dengan model visual yang menarik untuk dilihat.

\section{METODE PENELITIAN}

Setiap proses penulisan karya ilmiah diperlukan metode penelitian yang akan memudahkan dalam mencapai tujuan, sehingga akan mendapat informasi yang akurat.

Dalam penelitian yang dilakukan Henderi, et al [5] membahas tentang dashboard yang di dibuat dengan basis key performance indicator yang hasil akhirnya menciptakan sebuah tool enterprise performance management (EPM) berupa dashboard digital, sehingga data yang ditampilkan berupa data-data terfokus sesuai dengan kriteria yang sudah di tetapkan Metode penelitian yang digunakan.

Di sumber berbeda, metode sejenis dilakukan Raharja, Dkk [6] yaitu menggunakan metode pengembangan sistem perangkat lunak. Tahapan kegiatannya terdiri dari definisi masalah, analisa kebutuhan, perencanaan, 
pembuatan prorotipe, pemeliharaan, pengujian, dan implementasi.

Sedangkan dalam penelitian Handayani [7] juga menggunakan metode pengembangan sistem perangkat lunak, tetapi hanya dengan 4 tahapan, yaitu identifikasi kebutuhan, perencanaan perancangan prototype dan review prototype.

Dari beberapa penelitian tersebut, maka dalam penelitian ini penulis menggunakan metode pengembangan sistem perangkat lunak dan hanya menggunakan empat tahapan, yaitu analisa kebutuhan, perencanaan, perancangan prototype dan review protoype sebagai mana gambar 1 .

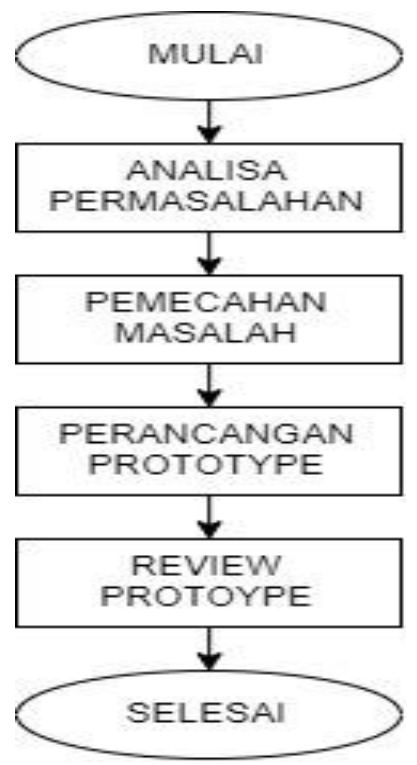

\section{Gambar 1. Tahapan Penelitian}

Gambar 1 mendeskripsikan bahwa tahapan pertama adalah menganalisa permasalahan yang ada, selanjutnya dalam pemecahan masalah dilakukan analisa, informasi apa saja yang dibutuhkan dan ingin ditampilkan dalam dashboard. Tahap berikutnya merancang prototype dan me-reviewnya.

\section{HASIL DAN PEMBAHASAN}

\subsection{Analisa Permasalahan}

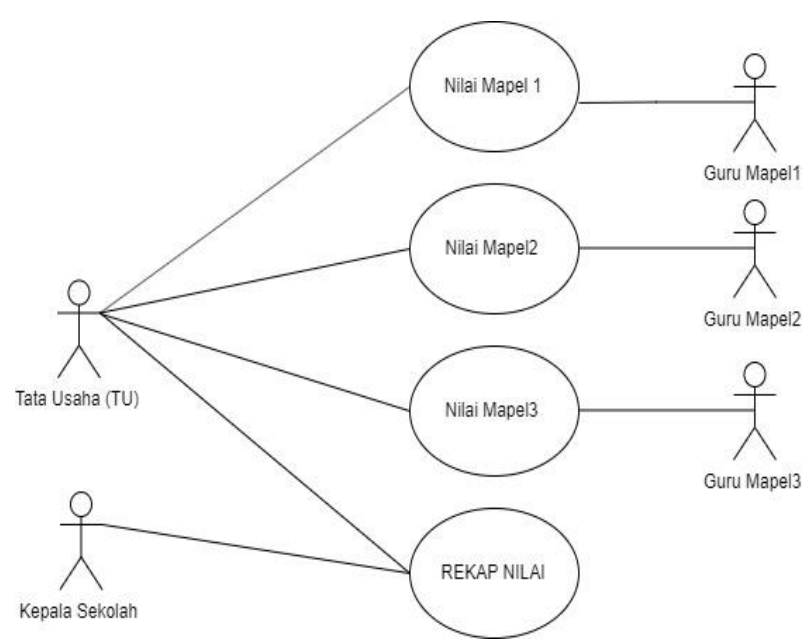

Gambar 2. Usecase Pelaporan Nilai

Pada gambar 2 dapat dilihat bahwa ada 2 permasalahan : (a) Masalah pertama guru mata pelajar (mapel)1 tidak dapat melihat langsung nilai yang di input oleh guru Mapel2 dan guru Mape13, begitu pula guru lain. (b) Masalah kedua bagi kepala sekolah mendapatkan rekap nilai berupa data penilaian yang banyak dan sulit dipahami.

Dari permasalahan tersebut dapat dilihat bahwa masih belum ada kemudahan dalah penyampaian informasi, dalam kasus ini adalah pelaporan nilai murid. Maka rumusan masalah yang ingin dipecahkan melalui penelitian ini adalah bagaimana merancang sebuah dashboard information system yang dapat diakses para tenaga pengajar dan kepala sekolah agar memudahkan dalam kolaborasi dan juga penyampian informasi lebih efisien. Dan data yang diolah oleh pihak sekolah masih berupa tabel excel seperti pada Tabel 1. 
Tabel 1. Data Penilaian Murid

\begin{tabular}{cccccc}
\hline No & Nama & Hadir & Sikap & Nilai & Ket \\
\hline $\mathbf{1}$ & ALDO & 75 & 80 & 76 & $\mathbf{b}$ \\
$\mathbf{2}$ & ALVIN & 77 & 85 & 80 & $\mathbf{s b}$ \\
$\mathbf{3}$ & ANGGI & 75 & 85 & 60 & $\mathbf{k b}$ \\
$\mathbf{4}$ & CIKA & 76 & 85 & 92 & $\mathbf{s b}$ \\
$\mathbf{5}$ & HARVEN & 80 & 85 & 88 & $\mathbf{s b}$ \\
$\mathbf{6}$ & LAUREN & 80 & 85 & 76 & $\mathbf{b}$ \\
$\mathbf{7}$ & JANSEN & 65 & 75 & 75 & $\mathbf{b}$ \\
$\mathbf{8}$ & JULIYUS & 70 & 75 & 36 & $\mathbf{k b}$ \\
$\mathbf{9}$ & REVAN & 79 & 85 & 68 & $\mathbf{k b}$ \\
\hline
\end{tabular}

Tampak pada tabel 1 terdapat 3 kriteria penilaian terhadap murid, yaitu penilaian kehadiran, penilaian sikap dan hasil nilai ujian. Dan 3 kriteria tersebut akan di tampilkan dalam bentuk dasboard. Sehingga menampilkan visualisasi yang lebih baik dan mudah diserap.

\subsection{Pemecahan Masalah}

Untuk menyelesaikan permasalahan yang ada di atas, maka di butuhkan sebuah sistem yang dapat menampilkan informasi dan dapat diakses oleh tenaga pengajar, bagian tata usaha dan kepala sekolah. Design dashboard dirancangan dengan bentuk yang baik sehingga dapat menyampaikan secara jelas, sesuai dengan penelitian Brath [8] ke efektifan dari sebuah design adalah hal yang penting agar informasi yang disampaikan bisa sampai dengan jelas kepada pengguna. Dalam hal ini penulis membuat dashboard menggunakan Microsoft Power BI. Dijelaskan bahwa Power BI dalam buku Microsoft Power BI Cookbook yang ditulis oleh Brett Powell [9] adalah sebuah perangkat yang digunakan untuk analisa bisnis dan pelayanan untuk kerjasama dalam mengakses sumber data, membentuk, menganalisa dan memvisualisasikan data serta berbagi wawasan.
Sehingga Power BI bisa digunakan untuk melakukan visualisasi nilai murid dan dapat diakses para tenaga pengajar.

\subsection{Perancangan Prototipe}

Dalam tahap perancangan, isian dashboard akan di buat menjadi beberapa bagian. Untuk mempermudah melihat informasi secara rinci. Sehingga pihak kepala sekolah mudah meyerap informasi yang ada. rancangan seperti terdapat pada gambar 3 .

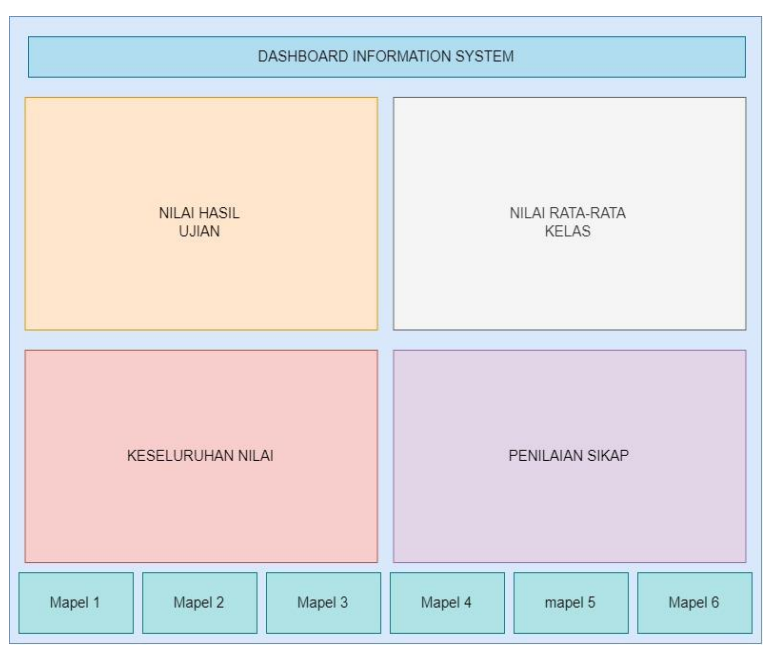

\section{Gambar 3. Rancangan Dashboard}

Tampak dalam gambar 3, informasi yang disajikan dibagi menjadi beberapa bagian, yaitu (a) Nilai hasil ujian untuk melihat siapa mendapat nilai terbaik ataupun sebaliknya pada suatu kelas dan akan ditampilkan dalam bentuk grafik seperti pada penelitian Listiyoko, et al [10] bentuk tabel di visualisasikan ke dalam bentuk grafik agar data mudah di analisa, (b) Nilai rata-rata kelas untuk melihat kemampuan guru dalam mengajar di suatu kelas/mata pelajaran (Mapel) hampir sama dengan penelitian altesa [11] yang menggunakan grafik perhitungan rata-rata dalam penjualan 
keseluruhan untuk melihat keuntungan, (c) Penilaian sikap untuk memonitoring prilaku murid, penilaian sikap di bagi menjadi 3 bagian, yaitu kurang baik, baik, sangat baik, (d) Keseluruhan nilai agar bisa melihat performa murid dari keseluruhan nilai. Dalam poin $\mathrm{c}$ dan $\mathrm{d}$ memiliki hasil yang berbeda dengan penelitian Siti Sarah [12] menggunakan rata-rata nilai tiap pelajaran untuk menilai hasil murid, (e) dashboard dibagi menjadi per-kelas/mapel agar penilaian bisa dilihat lebih rinci berbeda dengan penelitian Sulistiawati dan Heni [13] menggunakan dashboard untuk memonitoring perkembangan penjualan roti.

\subsection{Review Prototipe}

Protipe dashboard pada penelitian ini diimplementasikan sebagai media informasi data nilai siswa di SMK dharma Widya Tangerang. Hasil implementasi protipe dashboard ditunjukan Gambar 4.

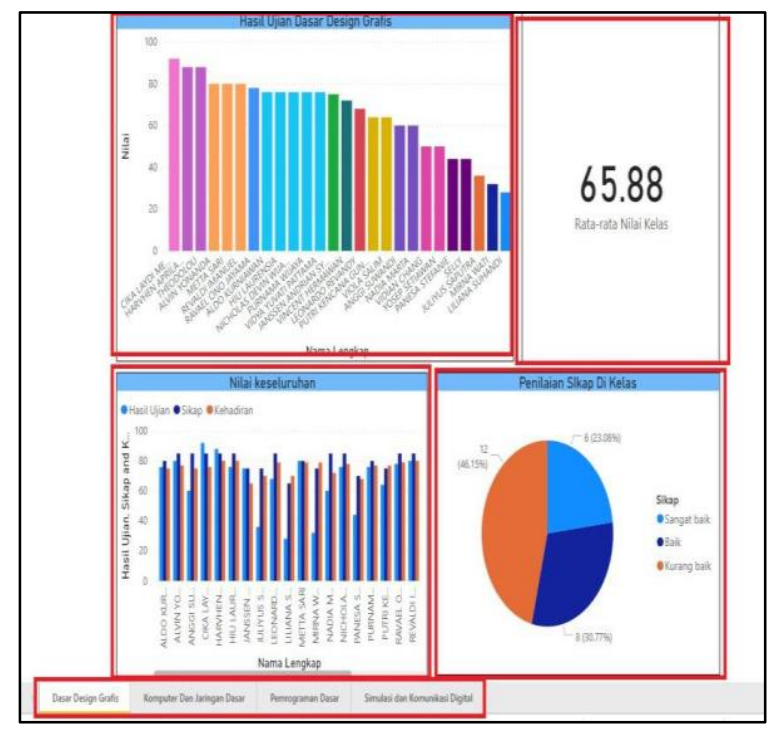

Gambar 4. dashboard information

Prototipe dashboard di Gambar 3 memuat informasi tentang nilai ujian mata pelajaran, nilai sikap di kelas, nilai keseluruhan, dan rertata nilai kelas. Prototipe dashboar yang dihasilkan dalam penelitian itu digunakan sebagai tools memantau evaluasi belajar.

1. Hasil nilai ujian permata pelajaran

Pada poin ini dapat dilihat bahwa nilai ujian ditampilkan berupa grafik, dan bisa dilihat nama siswa/siswi yang mendapat nilai tertinggi di mata pelajaran tersebut. Sehingga informasi tersebut bisa digunakan sebagai bahan pertimbangan pemberian reward untuk menambah motivasi murid yang lain.

\section{Penilaian sikap di kelas}

Para tenaga pengajar dapat melihat penilaian yang diberikan guru di kelas lain sehingga dapat membandingkan sikap murid saat belajar dikelas si guru dan dikelas guru lain. Sehingga para tenaga pengajar bisa memperbaiki kualitas dalam mengajar jika ada perbedaan sikap dari suatu murid.

3. Nilai keseluruhan dari 3 kriteria penilaian (nilai ujian, sikap, kehadiran)

Terdapat grafik yang dibentuk dari 3 kriteria yang ada sehingga memudahkan tenaga pengajar dalam memberikan sikap kepada masing-masing murid dan memberikan perhatian lebih kepada murid yang nilainya dibawah target.

\section{Rata-rata nilai kelas}

Nilai rata-rata kelas dapat menjadi poin perbandingan antara tenaga pengajar sebagai informasi bagi kepala sekolah. sehingga kepala sekolah dapat memberi masukan kepada masingmasing tenaga pengajar sesuai kualitasnya. 
5. Dashboard penilaian dibagi permata pelajaran

Dashboard dibuat secara terbagi di tiap mata pelajaran, sehingga kepala sekolah dapat melihat informasi lebih detail dan efektif. Informasi yang ada pada protipe dashboard di penelitian ini mengimplementasikan teori Henderi et al [5], yang menyatakan bahwa dashboard menggunakan 3 tahap aspek yang diutamakan, yaitu : data/informasi, personalisasi dan dapat digunakan sebagai media kolaborasi antar pengguna. Dengan demikian, informasi pada prototype dashboard mudah dipahami dan mudah di pantau lebih detail.

Dashboard juga menggunakan warnawarna yang membuatnya dapat memberikan informasi lebih tepat sehingga dapat memberikan tolak ukur dalam pengambilan keputusan. Pada penelitian ini, warna pada dashboard digunakan untuk menyorot data, menyandikan data, dan membuat hubungan antara masing-masing item di layar. Pilihan warna dibuat berdasarkan pada pemahaman tentang bagaimana user memandang warna dan pentingnya perbedaan warna.

\section{KESIMPULAN}

Kesimpulan dari sistem dashboard yang dibuat dapat mengatasi masalah yang ada, dapat di ambil kesimpulan dengan adanya dashboard sistem pelaporan nilai lebih efektif . Dasboard yang dihasilkan pada penelitian ini menghasilkan informasi berbentuk visual dan mudah dipahami, dan memudahkan guru dalam hal berkolaborasi.

Selain itu, dashboard yang dihasilkan dalam penelitian ini memudahkan kepala sekolah mengakses nilai murid, dan melihat hasil metode pengajaran yang digunakan para guru. Dengan demikian, dashboard juga dapat memberikan masukan kepada guru dalam hal meningkatan kualitas pembelajaran.

\section{DAFTAR PUSTAKA}

[1] Mulyono H. Perancangan Dashboard Sistem Untuk Penyajian Informasi Tingkat Pelanggaran Disiplin Siswa Pada Smk N 2 Lubuklinggau Berbasis Web. Jurnal Sistem Informasi Musirawas. 2016 Dec 1: 1 (1) pp. 19-30.

[2] Henderi H, Junaidi J, Kusuma TA. Dashboard Monitoring System Penjualan Dan Reward Mobile Kios PT. Telekomunikasi Seluler. Semantik. 2012 Jun 23: 2 (1).

[3] Ropianto M. Pemanfaatan Sistem Dashboard Pada Data Akademik Di Sekolah Tinggi Teknik (STT) Ibnu Sina Batam. Jurnal Teknik Ibnu Sina JT-IBSI. 2017 Oct 9;2(2).

[4] Rahardja U, Aini Q, Enay N. Optimalisasi Dashboard pada Sistem Penilaian Sebagai Media Informasi di Perguruan Tinggi. Sisfotenika. 2017 Aug 21;7(2):167-76.

[5] Henderi H, Rahayu S, Prasetyo BM. Dashboard Information System Berbasis Key Performance Indicator. InSeminar Nasional Informatika (SEMNASIF). 2015 Jul 9 (Vol. 1, No. 4).

[6] Rahardja U, Handayani I, Syoifana Y. Penerapan Viewboard Status Validasi Berbasis Yii Framework Pada PESSTA+ Di Perguruan Tinggi. Creative Information Technology Journal. 2019 Jan 12;4(4):297305.

[7] Handayani I, Febriyanto E, Solichin KR. Penerapan Viewboard Sebagai Media Informasi Sidang Skripsi Pada PESSTA+ di Perguruan Tinggi. Technomedia Journal. 2018 Apr 22;2(2):55-65.

[8] Brath R, Peters M. Dashboard design: Why design is important. DM Direct. 2004 Oct; $85: 1011285$.

[9] Powell B. Microsoft Power BI Cookbook: Creating Business Intelligence Solutions of Analytical Data Models, Reports, and Dashboards. Packt Publishing Ltd; 2017 Sept. 27 
[10] Listiyoko, L., Ardi, R. A., \& Maksum, A. 2018. Implementasi Live Dashboard Dalam Pengembangan Business Intelligence Pada ELearning Stmik Muhammadiyah Banten. SEMNASTEKNOMEDIA ONLINE, 6(1), 2-10.

[11] Yunistira, A. 2019. Analisis Penerapan Model Business Intelligence Pada Aplikasi PPOB (Payment Point Online Bankng) Dalam Menginktakan Stratgei Pemasaran (Studi Kasus: Aplikasi Apotikkouta). Program Studi Magister Teknik Informatika, Universitas Islam Indonesia, Yogyakarta

[12] Abdullah, S.S., 2019. Model Sisem Penilaian Capaian Pembelajaran Strata I Program Studi Teknik Informatika IKRA-ITH Informatika: Jurnal Komputer dan Informatika, 3 (1), pp. 86-93.

[13] Sulistiani, H. 2018. Perancangan Dashboard Interaktif Penjualan (Studi Kasus: PT. Jaya Bakery). Jurnal Tekno Kompak, 12(1), 15-17. 